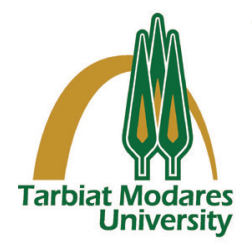

\title{
Considerations for Maintaining Safety in Biobanks during the COVID-19 Pandemic: A Systematic Review
}

\section{A R T I C L E I N F O}

\section{Article Type}

Review article

\section{Authors}

Aanuoluwapo Adeyimika Afolabi, $M P H^{1^{*}}$

Olayinka Stephen Ilesanmi, $P h D^{1,2}$

\section{A B S T R A C T}

Backgrounds: COVID-19 diagnostic testing and research substantially depend on highquality COVID-19 specimens, for which biobanks are an important repository. This systematic review aimed to highlight the considerations for maintaining safety in biobanks during the COVID-19 pandemic.

Materials \& Methods: A systematic review of literature was conducted using the guidelines of the Preferred Reporting Items for Systematic Reviews and Meta-Analyses. The literature search was conducted across Google Scholar, PubMed, and Directory of Open Access Journal because of their high indexation on many journals. Pre-defined search terms were used in the literature search. Overall, 7,184 articles were retrieved, and 2,054 duplicates among them were removed. After screening for eligibility using pre-defined criteria, 12 articles were included in the review.

Findings: Challenges faced by biobanks amid the COVID-19 pandemic include poor handling of COVID-19 specimens, poor sample collection, and sample contamination due to unclarified standard operating procedures. Strategies such as developing a framework for governing and monitoring the export of biological samples should be employed to overcome dangers eminent in the collection of biological samples. Total adherence to standard operating procedures should be ensured to maintain safety in COVID-19 samples collection, handling, and storage modalities. A deficit in material supply should be promptly addressed.

Conclusion: Compliance with issued guidelines should be ensured by the management and staff of COVID-19 biobanks.

Keywords: Biobanks, COVID-19, Safety of COVID-19 samples, COVID-19 research.

\section{CITATION LINKS}

${ }^{1}$ Department of Community Medicine, University of Ibadan, Ibadan, Oyo State, Nigeria

${ }^{2}$ Department of Community Medicine, University College Hospital, Ibadan, Oyo State, Nigeria

[1] World Health Organization... [2] Worldometer. COVID-19: Coronavirus... [3] Centers for Disease Control and Prevention. Interim guidelines ... [4] Yadav BK, Bihari C. Critical role of biobanks in ... [5] Allocca CM, Snapes E, Albert M, Bledsoe MJ, Castelhano MG, De Wilde M, et al. Biobanking in ... [6] Lankes HA, Makhlouf H. Biospecimen collection during the ... [7] World Health Organization. Novel coronavirus (2019-nCoV) technical ... [8] COVID P. 19: a safe handling and processing for samples in ... [9] Cloudlims. COVID-19 clinical data ... [10] Loibner M, Langner C, Regitnig P, Gorkiewicz G. Biosafety requirements for ... [11] Vaught J. Biobanking during the COVID-19 pandemic. Biopreserv ... [12] Peeling RW, Boeras D, Wilder-Smith A, Sall A, Nkengasong J. Need for ... [13] Centers for Disease Control and Prevention. Vaccines for ... [14] Moher D, Liberati A, Tetzlaff J, Altman DG. Preferred Reporting Items for ... [15] Allocca C, Bledsoe MJ, Albert M, Anisimov SV, Bravo E, Castelhano MG, et al. Biobanking in ... [16] Tumilasci V, Nowacki PM, Puchois P. The promise and plight of biobanking ... [17] Simeon-Dubach D, Henderson MK. Opportunities and risks for ... [18] Christoffels A, Abayomi A. Careful governance of African ... [19] Parichehreh-Dizaji S, Haghpanah V. Biosafety guidelines for ... [20] Hofman P, Puchois P, Brest P, Lahlou H, SimeonDubach D. Possible consequences of ... [21] Cannovo N, Cingolani M, Guarino R, Fedeli P. Regulation of biobanks in Italy. Front ... [22] Balcom D, Wolf L, Carrico RM, Marimuthu S, Al Haddad B, Malik DA. Implementation of the University of Louisville COVID-19 biorepository: Experiences from the Center of Excellence in Infectious Diseases (CERID). Univ Louisville J Respir ... [23] Food and Agricultural Organization. 2. Standard operating ... [24] Gurara D, Fabrizio S, Wiegand J. COVID-19: Without help, low-income developing countries risk a ... [25] de Vries J, Huijsman R. Supply chain management in health services: An overview. Supply Chain ... [26] GAO. COVID-19: Urgent actions needed to better ensure an effective federal ... [27] CSCMPs Supply Chain [Quarterly]. Strategy: COVID-19 and the health care supply chain: impacts and... [28] Miller FA, Young SB, Dobrow M, Shojania KG. Vulnerability of the medical product supply chain: The wake-up call of COVID-19. BMJ ... [29] Yang J-R, Liu M-T, Huang H-I, Teng H-J, Chen J-H, Li S-Y. Building the national SARS-Cov-2 laboratory diagnostic... [30] Paul S. Safety for biobanks: Strategies for safe COVID-19 specimens handling.

Biobanking; 2020.
Received:May 15,2021

Accepted: June 25,2021

Published: July 20,2021

Copyright(C) 2021, TMU Press. This open-access article is published under the terms of the Creative Commons Attribution-NonCommercial 4.0 International License which permits Share (copy and redistribute the material in any medium or format) and Adapt (remix, transform, and build upon the material) under the Attribution-NonCommercial terms. 


\section{Introduction}

The novel Coronavirus disease (COVID-19) is an infectious illness caused by the severe acute respiratory syndrome coronavirus-2 (SARSCoV-2) ${ }^{[1]}$. As of $29^{\text {th }}$ April 2021, 151,272,542 cases have been confirmed as positive through laboratory investigations ${ }^{[2]}$. In the COVID-19 context, specimen collection and testing are two key factors in ruling out other illnesses and enhancing diagnosis ${ }^{[3]}$. Nasopharyngeal swabs and stool specimens are collected from symptomatic and asymptomatic persons to ascertain individual's COVID-19 status ${ }^{[4]}$. Biobanking is an important tool in biomedical research, which promotes research activities by improving access to biological samples and clinical data for innovation and production of drugs [5]. Biobanks are an important repository for conducting diagnostic testing and research on high-quality COVID-19 specimens ${ }^{[4]}$. Due to the need to conduct more COVID-19 tests, active collaboration between public and private health institutions has been established ${ }^{[5]}$. The establishment of more biobanks has increased the coverage of tested persons, thus reducing the turnout time for result collection. Although biobanks continue to demonstrate their relevance to multiple grounds, biosafety concerns in managing biological COVID-19 samples exist ${ }^{[6]}$.

The World Health Organization has provided conditions for performing safe procedures in laboratories where COVID-19 samples are collected [7]. These conditions entail recommendations on safe sample collection and handling, transportation, disinfection, laboratory cleanliness, and storage of biological samples in exclusive safety cabinets during the COVID-19 pandemic. Building on these, biosafety guidelines have been developed by the government of many countries for COVID-19 biobanks ${ }^{[8-9]}$. The guidelines require observance of good laboratory practices and standard safety precautions while working with infectious samples [10]. Many COVID-19 biobanks are currently working under these recommended safety guidelines; however, others are defaulting in complete compliance to the safety recommendations.

The contributions of biobanking have been well demonstrated in the 1918 Spanish Influenza pandemic and the 2014-2016 Ebola outbreak in Africa. During these periods, the validation of the causative organisms of Influenza and Ebola was done via the collection of tissue samples [11]. During the Zika virus outbreak, rapid tests, such as antigen detection and serology tests, conducted at the point of care enhanced the generation of test results within a short while ${ }^{[12]}$. These tests are available in many nations across the globe, including low and middle-income countries, with high sensitivity and specificity for the detection of infectious diseases ${ }^{[12]}$. Access to Zika virus specimens was made possible via biobanks, and test development commenced ${ }^{[12]}$. Thus, biobanks provided an opportunity in these contexts to control infectious diseases. Maintaining high safety levels in biobanks is a key factor in preventing COVID-19 transmission to healthcare workers working in these facilities. COVID-19 vaccines have been administered to a large proportion of healthcare workers. However, these vaccines are not currently available for the entire population in many countries ${ }^{[13]}$. This calls for the need to maintain overall safety, especially in COVID-19 biobanks.

Objectives: Therefore, this systematic review aimed to highlight the considerations for maintaining safety in biobanks during the COVID-19 pandemic.

\section{Materials and Methods}

A systematic review of literature was conducted using the guidelines of the Preferred Reporting Items for Systematic Reviews and Meta-Analyses (PRISMA) ${ }^{[14]}$. 
All literature including reports related to COVID-19 sample collection as well as safety of healthcare workers working in COVID-19 biobanks or biorepositories were included in the study. The type of article was not used as a selection criterion, neither was the country in which the study was conducted used to select literature related to the research focus.

Database search: The literature search was conducted across three databases, namely: Google Scholar, PubMed, and Directory of Open Access Journal. These databases were selected because of their high indexation on many journals. As a result, a wide range of literature was retrieved.

To conduct the literature search, the following search terms were used, such as "COVID-19 AND Biobank", "Coronavirus AND Biobank", "COVID-19 tests AND Biobank", "SARS-CoV-2 AND Biobank", “COVID-19 OR Biobank", "COVID-19 OR Biobanking”, "Coronavirus OR Biobanking", "SARS-CoV-2 OR Biobanking", "COVID-19 specimen AND Biobanking", "COVID-19 specimen OR Biobanking", $\begin{array}{lcl}\text { "Coronavirus } & \text { AND } & \text { Biorepositories", } \\ \text { "Coronavirus } & \text { OR } & \text { Biorepositories", }\end{array}$ "COVID-19 AND Biorepositories", "COVID-19 OR Biorepositories", "SARS-CoV-2 AND Biorepositories", "COVID-19 biobanking AND standard operating procedures", "SARSCoV-2 AND Personal protective equipment", and "SARS-CoV-2 OR Biorepositories". All articles containing these search terms either in abstract, text, or keywords were included in the review. Only articles conducted between 2020 and 2021 were included. Both authors participated in the literature search to assess the eligibility of literature that met the inclusion criterion. In cases where both authors could not reach a consensus regarding the inclusion of a particular article, the consent of a third party was sought to ensure that bias was not introduced into the literature search.

Article screening and selection: The aforelisted databases and search terms were adopted in the literature search. A threestage method was adopted to conduct the article selection process (Figure 1):

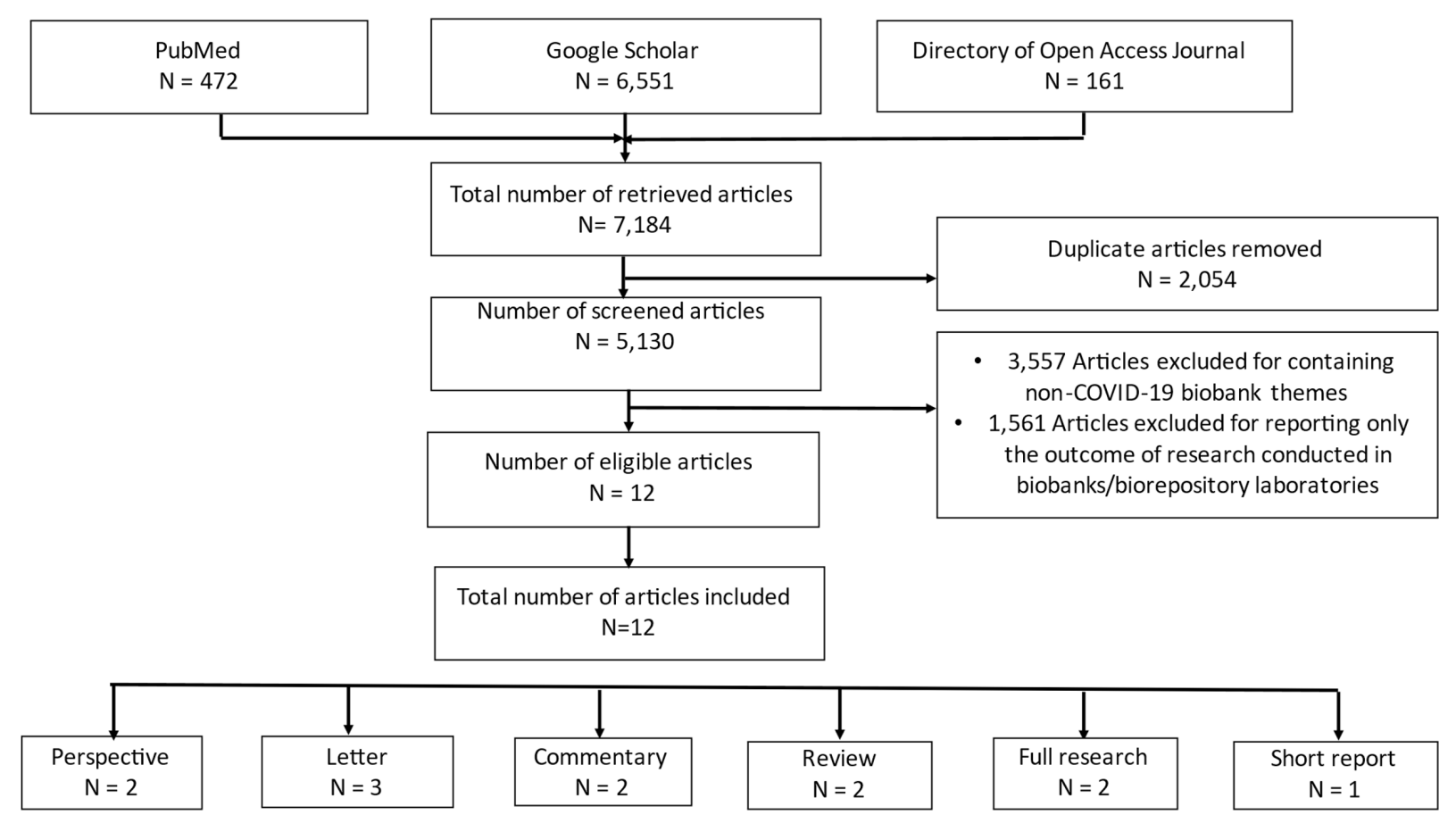

Figure 1) PRISMA flowchart showing the stage-wise article selection procedure 
Step One: Using the pre-defined search criteria, 7,184 articles were retrieved. Step Two: The article screening process was performed to remove duplicates. Overall, 2,054 duplicate articles were removed.

Step Three: Article screening was performed to exclude articles with themes not related to the safety of biological samples obtained from suspected or positive COVID-19 cases. Thus, a total of 5,611 articles were screened off. Among them, 3,557 were excluded because they did not contain themes related to COVID-19 biobanks, whiles 1,561 were excluded because they reported the outcome of research conducted on biobanks/ biorepositories only. Overall, 12 articles were selected as eligible and included in the review, namely two perspectives, three letters, two commentaries, two reviews, two full research studies, and one short report.

\section{Findings}

Challenges faced by COVID-19 biobanks: Allocca et al. (2020) in their full research article that sought to identify the needs and gaps in biobanking described biobanking challenges as follows: poor handling of COVID-19 specimens, poor sample collection, poor supply chain, and sample contamination [15].

Table 1 shows the summary of articles retrieved from the literature search. Tumilasci et al. (2020) in a book chapter described challenges faced by biobanks during the COVID-19 pandemic. The lack of structure in many biobanks has limited the responsiveness of biobanks during the COVID-19 pandemic [16].

Simeon-Dubach and Henderson (2020) in their commentary which addressed various opportunities and risks for research biobanks in the COVID-19 era and beyond described challenges such as poor compliance to standard operating procedures (SOPs) and lack of harmonization of standards in biobanking [17].

Strategies for improving safety in COVID-19 biobanks: In their full research article, Allocca et al. (2020) suggested solutions to address challenges faced by biobanks. These included the establishment of clear SOPs and training of biobank staff on risk management strategies [15].

In their letter-to-the-editor that aimed to identify the strategies of sample collection, processing, and analysis at the forefront of COVID-19, Vaught et al. (2020) reported that enhancing the safe handling of biological specimens is a key factor in ensuring safety of specimens and laboratory staff during the COVID-19 pandemic [11].

Christoffels and Abayomi (2020) described the strategies for overcoming dangers eminent in the collection of biological samples. These included the need to develop a framework for governing and monitoring the handling of biological samples, including SOPs ${ }^{[18]}$.

To improve international efforts on the diagnosis, treatment, and management of COVID-19 biological samples, ParichehrehDizaji and Haghpanah (2020) stressed the importance of SOPs in maintaining safety in the collection, handling, and storage modalities for COVID-19 samples. Appropriate identification and labelling of infectious specimens by appropriate labels and on electronic systems will reduce the possibility of cross-contamination between two or more specimens ${ }^{[19]}$.

Hofmann et al. (2020) in their letter described the options for preventing the contamination of samples collected from cancer patients with COVID-19 in biobanks. The options described included universal precautions as the gold standard while working on SARSCoV-2-infected samples. Also, separate storage of COVID-19 samples should be done to avoid cross-contamination ${ }^{[20]}$.

In a perspective article by Cannovo et al. 
Table 1) Summary of articles retrieved from literature search

\begin{tabular}{|c|c|c|c|c|c|}
\hline \multirow[b]{2}{*}{ Author List } & \multirow[b]{2}{*}{ Article Type } & \multirow[b]{2}{*}{ Title } & \multirow[b]{2}{*}{ Objective } & \multicolumn{2}{|l|}{ Findings } \\
\hline & & & & $\begin{array}{l}\text { Challenges of } \\
\text { Biobanks }\end{array}$ & $\begin{array}{l}\text { Strategies to Improve Safety in } \\
\text { COVID-19 Biobanks }\end{array}$ \\
\hline $\begin{array}{l}\text { Vaught et al., } \\
2020^{[11]}\end{array}$ & $\begin{array}{l}\text { Letter-to-the- } \\
\text { editor }\end{array}$ & $\begin{array}{l}\text { Biobanking during the } \\
\text { COVID-19 Pandemic }\end{array}$ & $\begin{array}{l}\text { To identify strategies for patient } \\
\text { sample collection, processing, } \\
\text { and analysis at the forefront of } \\
\text { COVID-19 }\end{array}$ & - & Safe handling of biological specimens \\
\hline $\begin{array}{l}\text { Christoffels } \\
\text { and Abayomi, } \\
2020^{[18]}\end{array}$ & $\begin{array}{l}\text { Letter-to-the- } \\
\text { editor }\end{array}$ & $\begin{array}{l}\text { Careful governance of } \\
\text { African biobanks }\end{array}$ & $\begin{array}{l}\text { To identify strategies for } \\
\text { overcoming dangers eminent } \\
\text { in the collection of biological } \\
\text { samples }\end{array}$ & - & $\begin{array}{l}\text { A framework for governing and } \\
\text { monitoring the handling of biological } \\
\text { samples, including standard SOPs need to } \\
\text { be developed }\end{array}$ \\
\hline $\begin{array}{l}\text { Parichehreh- } \\
\text { Dizaji and } \\
\text { Haghpanah, } \\
2020^{[19]}\end{array}$ & Commentary & $\begin{array}{l}\text { Biosafety Guidelines for } \\
\text { COVID-19 Specimens in } \\
\text { Biobanks }\end{array}$ & $\begin{array}{l}\text { To improve international efforts } \\
\text { on the diagnosis, treatment, } \\
\text { and improvement of COVID-19 } \\
\text { biological samples }\end{array}$ & - & $\begin{array}{l}\text { i. Maintenance of SOPs in the collection, } \\
\text { handling, and storage of COVID-19 } \\
\text { samples } \\
\text { ii. Regular updates on SOPs to avoid cross- } \\
\text { contamination between specimens } \\
\text { iii. Identification and labeling of infectious } \\
\text { specimens by appropriate labels and on } \\
\text { electronic systems }\end{array}$ \\
\hline
\end{tabular}

$\begin{array}{lll}\text { Hofmann etal., Letter-to-the- } & \begin{array}{l}\text { Possible consequences of } \\ \text { the COVID-19 pandemic } \\ \text { on the use of biospecimens } \\ \text { fo20 }\end{array} \\ & \begin{array}{l}{ }^{20]} \\ \text { research in academia and } \\ \text { bioindustry }\end{array}\end{array}$

$\begin{array}{ll}\text { Cannovo etal., } & \text { Perspective } \\ 2020^{[21]} & \begin{array}{l}\text { Regulation of biobanks } \\ \text { in Italy }\end{array}\end{array}$

To describe options for preventing the contamination of samples collected from cancer patients with SARS CoV-2 in biobanks i. Mandatory work on SARS-CoV-2 samples at biosafety level 2 (BSL-2) and class II biosafety workbenches should be ensured. ii. Separate storage of all human samples collected during the COVID-19 should be done
To present an overview of Italian legislation on research biobanks in a bid to describe the requirements for the collection of COVID-19 samples and their use
Collection and storage of biological samples in compliance with SOPs

\begin{tabular}{|c|c|c|c|c|c|}
\hline $\begin{array}{l}\text { Balcom et al., } \\
2020^{[22]}\end{array}$ & Short report & $\begin{array}{l}\text { Implementation of the } \\
\text { University of Louisville } \\
\text { COVID-19 Biobank: } \\
\text { Experiences from the } \\
\text { Center of Excellence for } \\
\text { Research in Infectious } \\
\text { Diseases (CERID) }\end{array}$ & $\begin{array}{l}\text { To describe the steps involved } \\
\text { in initiating a COVID-19 } \\
\text { biobank process }\end{array}$ & - & $\begin{array}{l}\text { i. All COVID-19 biological samples should } \\
\text { be treated as highly infectious } \\
\text { ii. Separate areas should be designated } \\
\text { for sample collection, sample inactivation, } \\
\text { sample preparation, sample extraction, } \\
\text { and sample testing }\end{array}$ \\
\hline $\begin{array}{l}\text { Yadav et al., } \\
2020^{[4]}\end{array}$ & $\begin{array}{l}\text { Full research } \\
\text { article }\end{array}$ & $\begin{array}{l}\text { Diverse responses of the } \\
\text { biobanks in Indo-Pacific } \\
\text { Rim region during the } \\
\text { COVID-19 Pandemic: } \\
\text { Case scenarios from two } \\
\text { low-and middle-income } \\
\text { countries and two high- } \\
\text { income countries in the } \\
\text { Indo-Pacific Rim Region }\end{array}$ & $\begin{array}{l}\text { To share the available } \\
\text { information and learn the } \\
\text { experiences of biobanks } \\
\text { concerning COVID-19 }\end{array}$ & - & $\begin{array}{l}\text { Standard operational and retraining } \\
\text { protocols should be maintained while } \\
\text { working on human specimens }\end{array}$ \\
\hline $\begin{array}{l}\text { Peeling et al., } \\
2020^{[12]}\end{array}$ & Perspective & $\begin{array}{l}\text { Need for sustainable } \\
\text { biobanking networks } \\
\text { for COVID-19 and other } \\
\text { diseases of epidemic } \\
\text { potential }\end{array}$ & $\begin{array}{l}\text { To highlight measures } \\
\text { for building sustainable } \\
\text { biobanking networks for } \\
\text { COVID-19 and other epidemics }\end{array}$ & - & $\begin{array}{l}\text { Stringent oversight and governance are } \\
\text { required }\end{array}$ \\
\hline
\end{tabular}




\begin{tabular}{|c|c|c|c|c|c|}
\hline \multirow{2}{*}{ Author List } & \multirow{2}{*}{ Article Type } & \multirow{2}{*}{ Title } & \multirow{2}{*}{ Objective } & \multicolumn{2}{|l|}{ Findings } \\
\hline & & & & Challenges of Biobanks & $\begin{array}{l}\text { Strategies to Improve Safety in } \\
\text { CoVID-19 Biobanks }\end{array}$ \\
\hline uired & $\begin{array}{l}\text { Full research } \\
\text { article }\end{array}$ & $\begin{array}{l}\text { Biobanking in the } \\
\text { coviD-19 Era and } \\
\text { Beyond: Part } 1 \text {. How } \\
\text { Early Experiences } \\
\text { Can Translate into } \\
\text { Actionable Wisdom }\end{array}$ & $\begin{array}{l}\text { To identify needs and gaps } \\
\text { in biobanking tools }\end{array}$ & $\begin{array}{l}\text { i. Poor handling of } \\
\text { COVID-19 specimens } \\
\text { ii. Poor sample collection } \\
\text { iii. Sample contamination } \\
\text { iv. Inappropriate labeling } \\
\text { v. Poor supply chain } \\
\text { vi. Low competence of } \\
\text { available personnel } \\
\text { vii. Lack of clarity in the } \\
\text { definition of SOPs for safe } \\
\text { handling, biosafety, and } \\
\text { appropriate labelling of } \\
\text { sample }\end{array}$ & $\begin{array}{l}\text { i. Establishment of clear SOPs } \\
\text { for safe handling of infectious } \\
\text { materials } \\
\text { ii. Training of biobank staff on risk } \\
\text { management strategies }\end{array}$ \\
\hline $\begin{array}{l}\text { Tumilasci et } \\
\text { al., } 2020^{[16]}\end{array}$ & Book chapter & $\begin{array}{l}\text { The promise and plight } \\
\text { of biobanking initiatives } \\
\text { during the COVID-19 } \\
\text { pandemic: The urgent } \\
\text { need to change existing } \\
\text { practices }\end{array}$ & $\begin{array}{l}\text { To describe the challenges } \\
\text { faced by biobanks during } \\
\text { the COVID-19 pandemic }\end{array}$ & A lack of proper structure & \\
\hline $\begin{array}{l}\text { Simeon- } \\
\text { Dubach and } \\
\text { Henderson, } \\
2020^{[17]}\end{array}$ & Commentary & $\begin{array}{l}\text { Opportunities and } \\
\text { Risks for Research } \\
\text { Biobanks in the } \\
\text { COVID-19Era and } \\
\text { Beyond }\end{array}$ & $\begin{array}{l}\text { To address various } \\
\text { opportunities and risks } \\
\text { for research on biobanks } \\
\text { in the COVID-19 era and } \\
\text { beyond }\end{array}$ & $\begin{array}{l}\text { i. Poor compliance to SOPs } \\
\text { in biobanks } \\
\text { ii. Absence of sustainability } \\
\text { measures for COVID-19 } \\
\text { biobanks } \\
\text { iii. Lack of harmonization } \\
\text { of standards in biobanking, } \\
\text { and irreproducibility of } \\
\text { test results }\end{array}$ & $\begin{array}{l}\text { Storage of all COVID-19 samples } \\
\text { in biosafety level- } 2 \text { laboratories or } \\
\text { higher laboratories } \\
\text { iii. The use of personal protective } \\
\text { equipment should be mandated for } \\
\text { use by all employees in biobanks }\end{array}$ \\
\hline $\begin{array}{l}\text { Lankes and } \\
\text { Makhlouf, } \\
2021^{[6]}\end{array}$ & Review & $\begin{array}{l}\text { Biospecimen } \\
\text { collection during the } \\
\text { COVID-19 pandemic: } \\
\text { Considerations for } \\
\text { Biobanking }\end{array}$ & $\begin{array}{l}\text { To describe the strategies } \\
\text { for proper biospecimen } \\
\text { handling necessary to } \\
\text { prevent laboratory-related } \\
\text { infections. }\end{array}$ & - & $\begin{array}{l}\text { i. Standard safety precautions } \\
\text { should be maintained while } \\
\text { handling or labelling COVID-19 } \\
\text { biological specimens. } \\
\text { ii. A minimum of Biosafety-Level-2 } \\
\text { should be ensured in COVID-19 } \\
\text { biosafety laboratories }\end{array}$ \\
\hline
\end{tabular}

(2020), which described the requirements for the collection of COVID-19 samples and their use, they stated the need for collection and storage of such samples in tandem with SOPs ${ }^{[21]}$.

While describing the steps involved in initiating a COVID-19 biobank process in a short report article, Balcom et al. (2020) recommended the classification of all COVID-19 samples as highly infectious samples which are to be collected, inactivated, extracted, and tested in separate areas ${ }^{[22]}$. In their full research article that highlighted the opportunities for improving the experiences of biobanks, Yadav et al. (2021) stressed that SOPs should be maintained in all biobanks ${ }^{[4]}$.

In their perspective study that highlighted the measures for building sustainable biobanking networks for COVID-19 and other epidemics, Peeling et al. (2020) described the need for stringent oversight and governance in COVID-19 biobanks ${ }^{[12]}$.

Lankes and Makhlouf (2021) in their review article described the strategies for proper biospecimen handling necessary to prevent laboratory-related infections. The need for maintaining SOPs and biosafety in biobanks is of utmost importance ${ }^{[6]}$.

\section{Discussion}

This review identified the challenges faced 
by biobanks as well as the requirements in biobanking operations needed to improve service delivery during the COVID-19 pandemic.

\section{Challenges faced by COVID-19 biobanks}

Lack of clarity on SOPs: SOPs have been identified as the bedrock on which laboratory investigations are based ${ }^{[22]}$. In the COVID-19 context, SOPs are required for the safe handling of biological samples obtained from individuals who may or may not be positive cases of COVID-19 [3, 17-19]. Clarity on these SOPs is however required by biobank staff to protect themselves against SARS-CoV-2 or prevent the transmission of COVID-19 to others ${ }^{[10]}$. The World Health Organization has developed a collection of guidance to support the safety of healthcare workers; in many instances, underestimation of the biosafety requirements is the norm ${ }^{[7]}$. Some of these biosafety requirements encompass the training and retraining of biobank staff [7]. Unfortunately, many of the personnel saddled with the responsibility to ensure biosafety requirements lack the required expertise to observe them [19, 23]. If these challenges are not addressed with a sense of urgency, the aim of establishing biobanks i.e., for research and innovation in disease management will be defeated.

Poor supply chain: In the healthcare sector, a supply chain refers to a series of processes involving different teams as well as the movement of products needed by healthcare workers to perform their duties [24]. When the supply chain is efficient, it leads to improved processes, efficiency in resource utilization, and patient satisfaction [24]. In the COVID-19 context, poor supply chain results in limited availability of Reverse Transcriptase Polymerase Chain Reaction tests to speed up COVID-19 testing among the population. Thus, delay in turnaround time for COVID-19 test result leads to reduced patient satisfaction ${ }^{[25]}$. In many instances, inadequate support from the government or the Ministry of Health in each country culminates in a poor supply chain and logistical support [26-27].

Strategies to improve safety in COVID-19 biobanks Availability of clear and updated SOPs: The safety of biospecimens could be maintained by ensuring overall safety precautions, regular risk assessments, adherence to SOPs, as well as regular training of biobank staff. Biobank staff training reduces the risk of errors made by biobank staff while working on COVID-19 samples [7]. To validate the test results of COVID-19 samples, it is required that quality assurance of biobanks is done at regular intervals ${ }^{[16]}$. The establishment and functionality of a laboratory management information system reduces errors due to mis-labelling and improper handling of biospecimens. Proper handling preserves the integrity and quality of COVID-19 samples and enhances the possibility of obtaining similar results when multiple tests are repeated on the samples [2].

Maintenance of biosafety levels: To ensure biosafety of COVID-19 samples, biosafety level (BSL) -2 rules must be strictly adhered to during diagnostic testing using automated instruments, especially when conducting histological analysis ${ }^{[28]}$. Culture of COVID-19 samples should however be conducted in BSL-3 laboratories that provide a higher level of protection and safety for biobank staff. Biological safety cabinets containing a high-efficiency particulate air (HEPA) filter should be used to conduct examinations on COVID-19 samples ${ }^{[28]}$. During culturing, HEPA filters should be used alongside HEPAfiltered incubators ${ }^{[29]}$. Although specimens are all placed in designated containers, decontamination of specimen container should be promptly done immediately after each specimen is removed from the safety cabinet. 
Use of Personal Protective Equipment (PPE): Regular use of PPE is very important to maintain the safety of COVID-19 samples in biobanks. The PPE could include face shields, disposable gloves, safety boots, and laboratory gowns [7]. This would ensure that potential contamination of a specimen with others is averted. After conducting examinations on the biological specimens, storage of the samples should be done in BSL-2 or BSL-3 laboratories. Likewise, COVID-19 specimens must be handled with care as highly infectious materials. While storing on a short-term basis, COVID-19 specimens should be stored at $2-8{ }^{\circ} \mathrm{C}$ in a viral medium ${ }^{[7]}$. The disposal of used PPE should be done carefully, as these are also infectious materials. Doffing of PPE should be done before exiting the laboratory, and proper handwashing with soap and under running water should be practiced.

Good governance: Governance encompasses a wide range of decision-making functions undertaken by governments/decision makers to achieve the objectives of the national health policy in ways that enhance universal health coverage ${ }^{[10]}$. In relation to COVID-19 biobanks, the leaders in the health sector are required to develop guidelines that are adapted to the local context in ways that assure patient safety as well as promote COVID-19-related innovation and research.

\section{Strengths and Limitations}

This study could have been limited in scope because it was not defined for a specific country. Despite this limitation, we presented a robust description of opportunities inherent in biobanking during the COVID-19 pandemic, and how biobanking operations could be improved globally.

\section{Conclusion}

Biobanking is believed to be useful in understanding COVID-19, enhancing diagnosis, soundly administering recently developed COVID-19 vaccines such as AstraZeneca, and developing other potent COVID-19 vaccines. However, maintaining the quality and safety of COVID-19 biospecimens should be ensured and assured. Regular quality assurance needs to be considered by standard organizations for all public and private laboratories where COVID-19 samples are collected. Also, total compliance to safety protocols should be mandated between the government and all laboratories involved in COVID-19 sample collection. In addition, rules should be made by policy makers and health institutions against the misuse of biological specimens for selfish purposes, and individuals involved in the injudicious use of these samples should be faced with the wrath of the law.

Acknowledgment: Not applicable. Ethical Permission: Not applicable. Conflict of interest: There are no conflicts of interest.

Author's contribution: Conceptualization: Both Authors,; Data curation and formal analysis:Both Authors,; Investigation:Both Authors,; Methodology and project administration: AAA,; Supervision: AAA,; Validation:Both Authors,; Writing of original draft: Both Authors; Writing, reviewing, and editing:Both Authors.

Fundings: None.

Consent to participate: Not applicable.

\section{References}

1. World Health Organization. Coronavirus. World Health Organization; 2021.

2. Worldometer. COVID-19: Coronavirus pandemic. 2021.

3. Centers for Disease Control and Prevention. Interim guidelines for collecting and handling of clinical specimens for COVID-19 testing. CDC; 2021.

4. Yadav BK, Bihari C. Critical role of 
biobanks in COVID-19 pandemic. Indian J Exp Biol. 2021;59:7-10.

5. Allocca CM, Snapes E, Albert $M$, Bledsoe MJ, Castelhano MG, De Wilde $M$, et al. Biobanking in the COVID-19 era and beyond: Part 2. A set of tool implementation case studies. Biopreserv Biobank. 2020;18(6):547-60.

6. Lankes HA, Makhlouf H. Biospecimen collection during the COVID-19 pandemic considerations for biobanking. Am J Clin Pathol. 2021;155(1):55-63.

7. World Health Organization. Novel coronavirus (2019-nCoV) technical guidance: laboratory testing for 2019nCoV in humans. Geneva, Switzerland: World Health Organization; 2021.

8. COVID P. 19: a safe handling and processing for samples in laboratories. UK: Public Health, 2020.

9. Cloudlims. COVID-19 clinical data management using LIMS. Cloudlime; 2020 .

10. Loibner $M$, Langner $C$, Regitnig $P$, Gorkiewicz G. Biosafety requirements for autopsies of patients with COVID-19: Example of a BSL-3 autopsy facility designed for highly pathogenic agents. Pathobiology. 2021;88(1):37-45.

11. Vaught J. Biobanking during the COVID-19 pandemic. Biopreserv Biobank. 2020;18(3):153-4.

12. Peeling RW, Boeras D, Wilder-Smith A, Sall A, Nkengasong J. Need for sustainable biobanking networks for COVID-19 and other diseases of epidemic potential. Lancet Infect Dis. 2020;20(10):e268-73.

13. Centers for Disease Control and Prevention. Vaccines for COVID-19. CDC; 2021.

14. Moher D, Liberati A, Tetzlaff J, Altman DG. Preferred Reporting Items for Systematic Reviews and Meta-Analyses: The PRISMA Statement. PLoS Med. 2009;6(7):e1000097.
15. Allocca C, Bledsoe MJ, Albert M, Anisimov SV, Bravo E, Castelhano MG, et al. Biobanking in the COVID-19 era and beyond: Part 1. How early experiences can translate into actionable wisdom. Biopreserv Biobank. 2020;18(6):533-46.

16. Tumilasci V, Nowacki PM, Puchois P. The promise and plight of biobanking initiatives during COVID-19 pandemic: The urgent need to change existing practices. Trans-Hit Biomarkers Whitepaper; 2020, pp.1-5.

17. Simeon-Dubach D, Henderson MK. Opportunities and risks for research biobanks in the COVID-19 era and beyond. Biopreserv Biobank. 2020;18(6):503-10.

18. Christoffels A, Abayomi A. Careful governance of African biobanks. Lancet. 2020; 395(10217):29-30.

19. Parichehreh-Dizaji S, Haghpanah V. Biosafety guidelines for COVID-19 specimens in biobanks. Biopreserv Biobank. 2020;16(6):587-91.

20. Hofman P, Puchois P, Brest P, Lahlou H, Simeon-Dubach D.Possibleconsequences of the COVID-19 pandemic on the use of biospecimens from cancer biobanks for research in academia and bioindustry. Nat Med. 2020;26(6):809-10.

21. Cannovo N, Cingolani M, Guarino R, Fedeli P. Regulation of biobanks in Italy. Front Pediatr. 2020;415(8):1-5.

22. Balcom D, Wolf L, Carrico RM, Marimuthu S, Al Haddad B, Malik DA. Implementation of the University of Louisville COVID-19 biorepository: Experiences from the Center of Excellence in Infectious Diseases (CERID). Univ Louisville J Respir Infect. 2020;4(1):1-12.

23. Food and Agricultural Organization. 2. Standard operating procedures. FAO; 2021.

24. Gurara D, Fabrizio S, Wiegand J. COVID-19: Without help, low-income developing countries risk a lost decade. 
IMFBlog; 2021.

25. de Vries J, Huijsman R. Supply chain management in health services: An overview. Supply Chain Manag. 2011;16(3):159-65.

26. GAO. COVID-19: Urgent actions needed to better ensure an effective federal response- report to congressional committees. 2021.

27. CSCMPs Supply Chain [Quarterly]. Strategy: COVID-19 and the health care supply chain: impacts and lessons learned. 2021.

28. Miller FA, Young SB, Dobrow M, Shojania KG. Vulnerability of the medical product supply chain: The wake-up call of COVID-19. BMJ Qual Saf. 2020;3(4):331-5. 29. Yang J-R, Liu M-T, Huang H-I, Teng H-J, Chen J-H, Li S-Y. Building the national SARSCov-2 laboratory diagnostic capacity in Taiwan. Health Secur. 2020;18(5):383-91.

30. Paul S. Safety for biobanks: Strategies for safe COVID-19 specimens handling. Biobanking; 2020. 